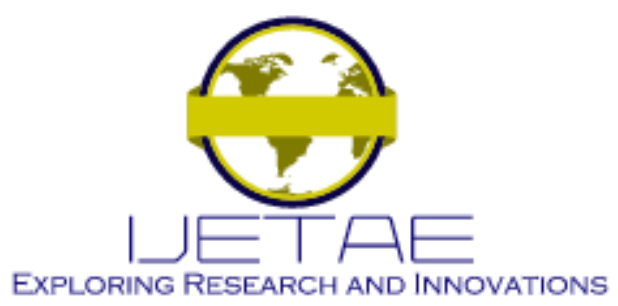

International Journal of Emerging Technology and Advanced Engineering

Website: www.ijetae.com (E-ISSN 2250-2459, Scopus Indexed, ISO 9001:2008 Certified Journal, Volume 11, Issue 09, September 2021)

Manuscript Received: 04 August 2021, Received in Revised form: 06 September 2021, Accepted: 14 September 2021

DOI: 10.46338/ijetae0921_02

\title{
Characterization of Electromagnetic Device by Means of Spice Models
}

\author{
Aldo Canova $^{1}$, Giambattista Gruosso ${ }^{2}$, Michele Quercio ${ }^{3}$ \\ ${ }^{1,3}$ Dipartimento Energia, Politecnico di Torino, Corso Duca degli Abruzzi 24, I-10129 Torino, Italy \\ ${ }^{2}$ Dipartimento di Elettronica Informazione e Bioingegneria, Politecnico di Milano, Piazza Leonardo Da Vinci 32,20133 Milano, \\ Italia
}

\begin{abstract}
In this paper, the lumped parameter circuital approach devoted to the simulation of massive, conductive, and ferromagnetic cores including eddy currents and nonlinearity is presented. In the first part of the paper, the circuit analogies devoted to the simulation of magnetic structure coupled with external electrical and eventually mechanical equations are summarised. The two techniques are known in the literature as reluctance-resistance and permeancecapacitance analogies. In particular, it is put in evidence the exploitation of the gyrator component in the modelling of the coupling among magnetic and electrical quantities. The originality of this paper consists in demonstrating for the first time that the rotator-capacitor approach is very suitable for simulations in spice environment and the solution is validated on real applications. Following the circuital approach, the effect of the conductivity and nonlinear magnetic behaviour of the magnetic branches is formalized and introduced in the model. The simulation of the conductivity behaviour, which introduces in massive cores significant eddy current effects, is modelled according to the two possible analogies: the reluctance and the permeance-capacitor model. Under sinusoidal steady-state behaviour, energy aspects related to the two models are then presented and discussed. The nonlinearity is taken into account through the fixed-point technique which is suitable for a lumped circuit representation. The full circuital approach is then adopted for the simulation of the real electromechanical actuator under transient and sinusoidal steady-state behaviour conditions. The simulated result is then compared with numerical finite element and experimental results.
\end{abstract}

Keywords - Actuator, Eddy currents, Magnetic circuit, Magnetic Non linearity, Permeance Analogy, Reluctance Analogy

\section{INTRODUCTION}

Modelling the magnetic structure through an electrical equivalent network is not a new topic in electrical engineering.
Since the last century, several authors have developed a generalized network theory, known as magnetic equivalent circuits (MEC) theory, to describe the behaviour of electromagnetic devices by using the rules of electric circuit theory [1][2][3][4][5]. The MEC method has traditionally been based on resistance-reluctance analogy and different authors have written on the use of this analogy to model static and dynamical effects in magnetic structures. The works of Buntenbach, Blanken, and Hamill [6-11] have focused the attention on a new way to model magnetic structures using the capacitance-permeance analogy. The method of magnetic circuits originally introduced by Carpenter [6], [9] has been deepened and introduced in the solution of electromechanical systems by Butebach [7-8]. This approach which preserves the topology, however, does not respect the physical analogy, so some modifications were introduced by Blanket [10] and Hamil [11]. The latter exploits a duality of the system so that the mathematical properties are preserved even if the topology is not preserved. We found that the gyratorcapacitor approach is particularly well suited for fieldcircuit simulations in the spice environment. Therefore, we decided to validate the two models and compare them with each other in a systematic way to determine their pros and cons. From reviewing the literature in recent years, this is the first time such a systematic comparison has been made. At the same time, particular attention has been devoted especially for the modelling of eddy current inside massive magnetic cores [12], [13]. The two representations proposed require different criteria to link each other the two domains; each of them introduces different dynamical and energy behaviour that is not only formally different. The simulation of magnetic devices, like the transformers, the inductances, or the electrical machines, directly coupled with driving circuit or with power electronic systems is one of the researchers' frontiers in the field of modelling of dynamical systems [26]. 


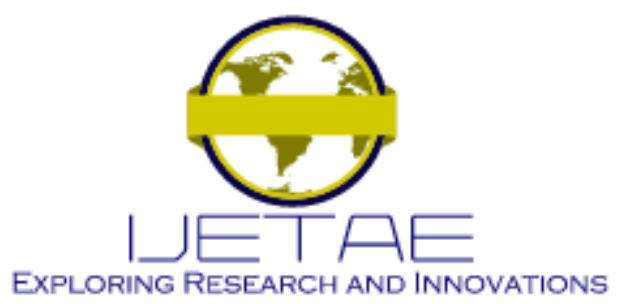

International Journal of Emerging Technology and Advanced Engineering

Website: www.ijetae.com (E-ISSN 2250-2459, Scopus Indexed, ISO 9001:2008 Certified Journal, Volume 11, Issue 09, September 2021)

In this scenario, MEC could represent a possible solution, but they have to be improved to take into account other electromagnetic phenomena by introducing nonlinear effects and eddy currents. In literature the magnetic non-linearity has been treated through different techniques, here the attention has been focused on one of them called the Fixed Point (FP) scheme. The fixed point method has potential for the simulation of non-linear magnetic systems [27]. At first, the method has been proposed by Chiampi et al. [18] to model magnetic non-linearity in the finite element method. In this paper, a method for modelling electromechanical systems based on an analogy with electrical circuits is presented. The originality of this paper is to be found mainly in the following aspects:

- a gyrator-capacitor based approach is analyzed and formalized highlighting its potential in the simulation of nonlinear magnetic phenomena in simulation tools based on nodal analysis.

- Two magnetic components (transformer and electromagnet) of great interest in industrial applications are studied, showing how the proposed method is well suited to the field-circuit co-simulation.

- Results are compared with field measurements, and it is the first time that the gyrator-capacitor approach is validated with experimental measurements.

A numerical comparison between the two approaches (Reluctance based and Permeance based) is presented for the first time. It is then applied the method of Permeance, which proves to have some benefits, to the study of a real problem and is validated through experimental measurements. A particular focus is then offered on the use of fixed point based non-linearity modelling techniques, which is shown to be more effective than the NewtonRaphson methods normally used in circuit simulation. The organization of the paper is the following: in section 2 the magnetic model is presented, then in section 3 the coupling methodology with external circuits is highlighted. In section 4 will be presented the eddy current model integrated with the magnetic one, while in section 5 some consideration on the power losses calculation are reported. Section 6 will be devoted to the description of the nonlinear modelling and solution of the network and finally in section 7 will be reported the main results. The last section will report the conclusion of the work.

\section{MAGNETIC MODEL}

\section{A. Reluctance-resistance analogy}

The traditional approach to Magnetic Equivalent Circuit (MEC) is based on the analogies between magneto motive force (MMF) and electrical voltage and between magnetic flux and electrical current. In this approach, the permeability can be considered the analogous of the conductivity so that the reluctance becomes the equivalent of electrical resistance. The relation between electrical and magnetic entities is reported in Table I. The constitutive equation (2) of the problem, into the magnetic domain, can be written employing the analogies in table I, starting from Ohm's law for the electrical circuit (1):

$$
i=\frac{v}{R}
$$

where $\mathrm{R}$ is the electrical resistance of the current flux tube. In case of a straight piece of conductor with length 1 and uniform cross section A

$$
\begin{aligned}
R= & \frac{l}{\sigma \cdot A} \\
& \Phi=\frac{F}{R}(2)
\end{aligned}
$$

in which $\mathrm{R}$ is the reluctance of a magnetic flux tube.

Table 1.

Reluctance-Resistance Analogy

\begin{tabular}{llll}
\hline Magnetic Circuit & & \multicolumn{2}{c}{ Electrical Circuit } \\
\hline mmf & $\mathrm{F}_{[\mathrm{At}]}$ & Voltage & $v_{[\mathrm{V}]}$ \\
Flux & ${ }^{f}[\mathrm{~Wb}]$ & Current & $\mathrm{i}_{[\mathrm{A}]}$ \\
Permeability & $\mu[\mathrm{H} / \mathrm{m}]$ & Conductivity & $\sigma[\mathrm{S} / \mathrm{m}]$ \\
& & & \\
Reluctance & $\mathrm{R}_{\left[\mathrm{H}^{-1}\right]}$ & Resistance & $R[\Omega]$ \\
& & & \\
\hline
\end{tabular}

Under these hypotheses, the magnetic structure could be considered divided into flux tubes in series, if the magnetic flux across the section is the same, or in parallel, if the MMF acting on each tube is the same. The topology of the MEC is then similar to the magnetic structure. Each winding of the structure can be represented through an ideal voltage source of value $\mathrm{Ni}$ where $\mathrm{N}$ is the number of turns around the magnetic core and $\mathrm{i}$ is the winding current. 


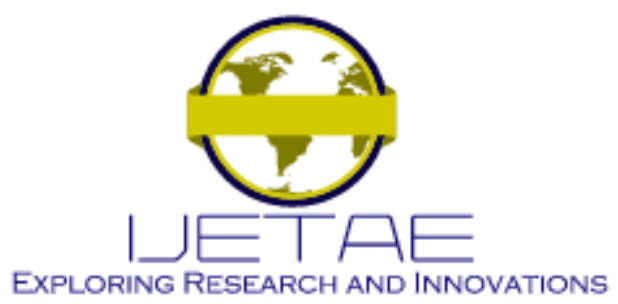

International Journal of Emerging Technology and Advanced Engineering

Website: www.ijetae.com (E-ISSN 2250-2459, Scopus Indexed, ISO 9001:2008 Certified Journal, Volume 11, Issue 09, September 2021)

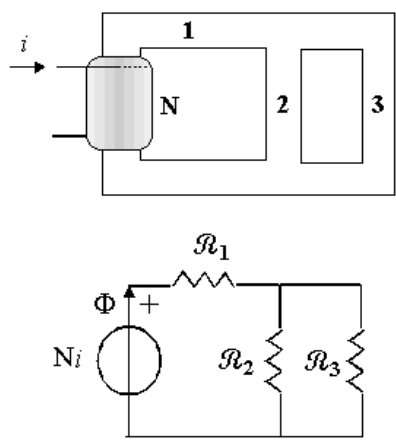

Figure 1. Reluctance-Resistance analogy MEC of a magnetic structure

\section{B. Permeance-capacitance analogy}

The previous model is easy to implement but presents many incongruities. For instance, the resistance, analogy of permeance, is a dissipative component while the actual behaviour of magnetic material is conservative. This issues, that are not relevant in the analysis of static electromagnetic device, acquire significance in power electronics or dynamic of electromechanical actuators [19]. Starting from energy consideration on the magnetic phenomena it is possible to introduce a new analogy that stores the relation between MMF and electrical voltage but introduces a new connection between flux rate $\Psi$ and electrical current. Now the permeability becomes an analogy of the permittivity and the permeance an analogy of the capacitance. The new constitutive equations (4), written using the analogies of table II, are derived directly from (2) rewritten in the following way:

$$
\Phi=\frac{F}{R}=P \cdot F
$$

in which $P=\frac{1}{R}$

$$
\Psi=\frac{d \Phi}{d t}=P \cdot \frac{d F}{d t}(4)
$$

The differential equation (4) corresponds to the constitutive equation of capacitance (5) in electrical circuits.

$$
i=C \frac{d v}{d t}(5)
$$

Moreover, in this model, the magnetic structure can be represented by the mean of "electrical" component connected in series or parallel, maintaining the same topology, as shown in figure $2[11,21]$.

\begin{tabular}{|c|c|c|c|}
\hline \multicolumn{2}{|c|}{ Magnetic Circuit } & \multicolumn{2}{|c|}{ Electrical Circuit } \\
\hline $\mathrm{mmf}$ & $\mathrm{F}[\mathrm{At}]$ & Voltage & $v[\mathrm{~V}]$ \\
\hline Flux rate & $\Psi[\mathrm{Wb} / \mathrm{s}]$ & Current & $i[\mathrm{~A}]$ \\
\hline Flux & $f=\int \Psi \cdot d t[\mathrm{~Wb}]$ & Charge & $q=\int i \cdot d t[C]$ \\
\hline Permeabilit & $\mu[\mathrm{H} / \mathrm{m}]$ & Permittivity & $\varepsilon[\mathrm{F} / \mathrm{m}]$ \\
\hline $\begin{array}{c}\mathrm{y} \\
\text { Permeance }\end{array}$ & $\mathbf{P}[\mathrm{H}]$ & Capacitance & $c[\mathrm{~F}]$ \\
\hline Power & $\mathrm{F} \cdot \Psi[\mathrm{W}]$ & Power & $v \cdot i[W]$ \\
\hline
\end{tabular}

Table 2.

Permeance-Capacitance Analogy
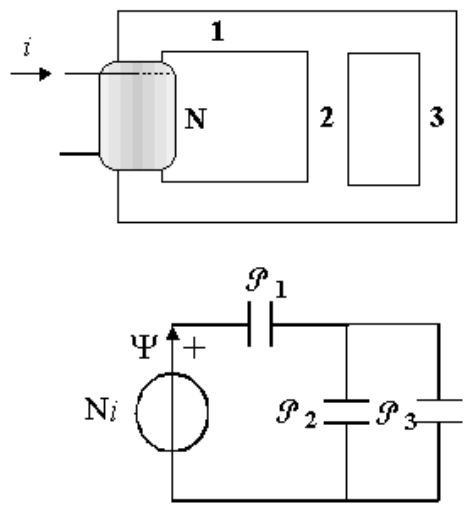

Figure 2.Permeance-Capacitance analogy MEC of a magnetic structure

\section{COUPLing With EXTERnAl CIRCUIT}

The choice of the interface between the electrical and magnetic domain requires particular attention. This coupling affects not only quantities like MMF and current or flux and voltage, but also exchanged power and energy. From this point of view, the link could be realized between two ports with different features following the two analogies. It must be remarked that the power absorbed by the magnetic structure can be evaluated only on the electric circuit port, while it is impossible to evaluate power on the magnetic side. This drawback does not hold in the permeance-capacitance analogy [21,22,23]. The link is obtained using the gyrator (fig. 3). The main feature of this ideal lossless component is that the active power remains the same measured on the right or left side of the two ports, while the reactive power changes sign. Capacitive power on the right side becomes inductive power on the left side. 


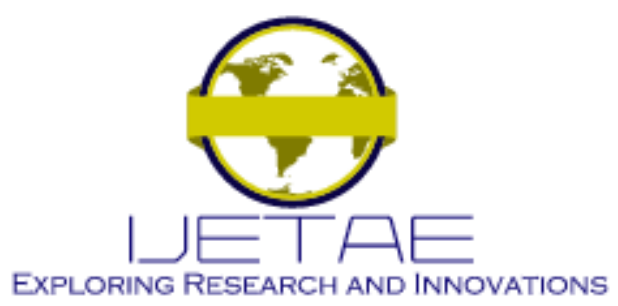

International Journal of Emerging Technology and Advanced Engineering

Website: www.ijetae.com (E-ISSN 2250-2459, Scopus Indexed, ISO 9001:2008 Certified Journal, Volume 11, Issue 09, September 2021)

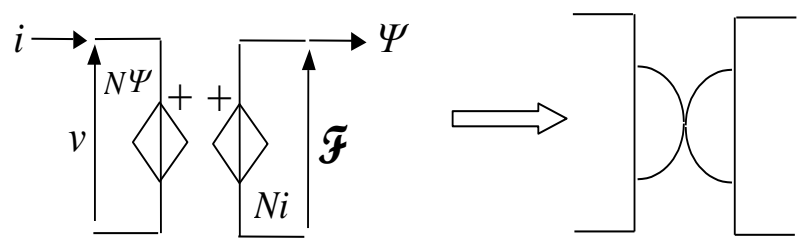

Figure 3. Two ports representation of electrical to magnetic coupling in permeance capacitance analogy by mean of gyrator $(N$ is the number of turns)

The two ports representation is:

$$
\left(\begin{array}{l}
V(t) \\
i(t)
\end{array}\right)=\left|\begin{array}{ll}
0 & N \\
\frac{1}{N} & 0
\end{array}\right| \cdot\left(\begin{array}{l}
F(t) \\
\Psi(t)
\end{array}\right)
$$

\section{EDDY CURRENT MODEL}

The electromagnetic structure is divided into a finite number of parts (magnetic branch) [24], [25]. According to the magnetic reluctance theory each of them is considered a flux tube. To take into account the eddy current effect is necessary to subdivide the magnetic branch into a certain number of slices. Each of them can be considered as a coil that links a flux share. For example, in Fig. 4 is reported a possible discretization of a cylindrical core. In each slice, the flux distribution and the induced eddy current are uniformly distributed.

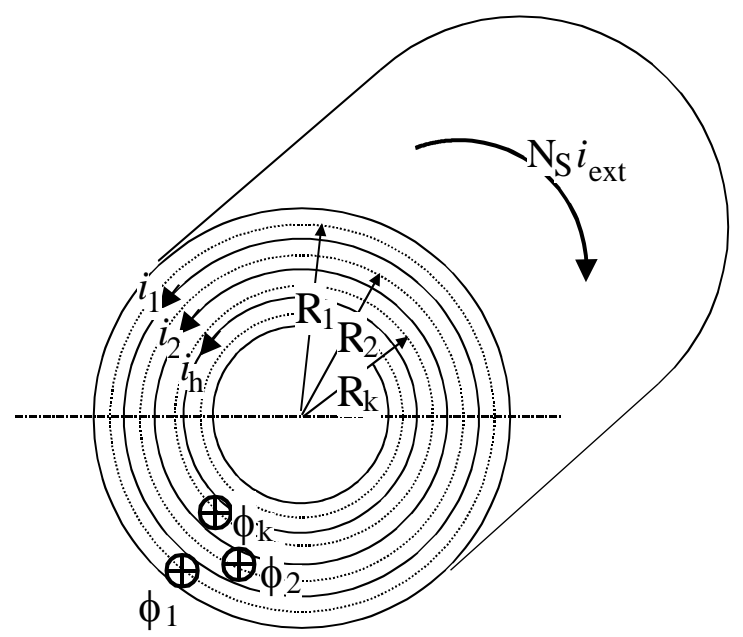

Figure 4.Cylindrical core subdivision

The conductance of a slice thick $\mathrm{dr}$ at the radius Rk with conductivity $\sigma$ can be written as:

$$
G_{h}=\sigma \cdot \frac{l_{0} \cdot d r}{2 \cdot \pi \cdot r_{h}}
$$

where la is the length of flux tube.

The first layer represents a conductive closed loop in which is induced a current proportional to the total flux linked with the layer. This current flows in the opposite direction of the windings current. For this reason, the mmf applied to the inner layer is given by:

$$
m m f^{\prime}=N I_{\theta x t}-\frac{1}{R_{1}} \sum_{k=2}^{N} \frac{d \phi_{k}}{d t}(8)
$$

The previous considerations are right for the second layer supplied by mmf'. Proceeding in this scheme is possible to obtain a ladder network as shown in Fig. 5.
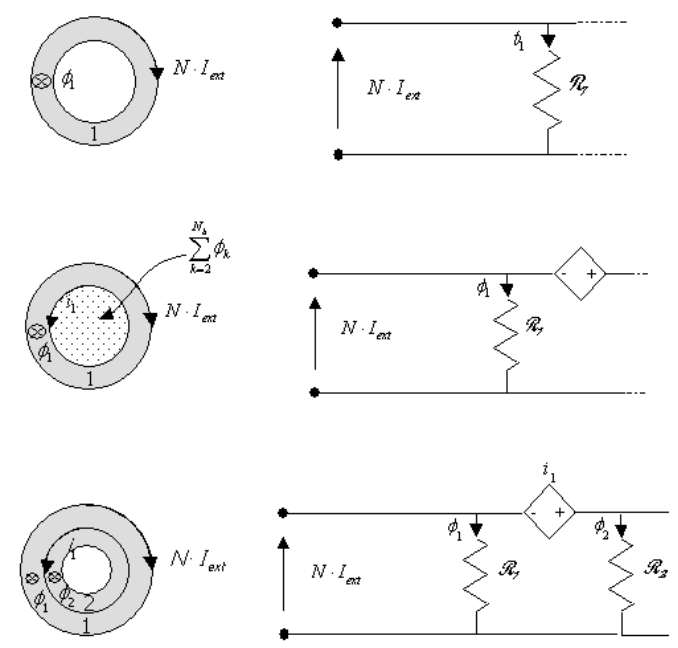

Figure 5.Functional scheme of network building

A lumped equivalent circuit of each magnetic branch can be obtained considering the transformer coupling between the "eddy current path" and the flux share across it. In Fig. 6 the reluctance-resistance analogy model is reported.

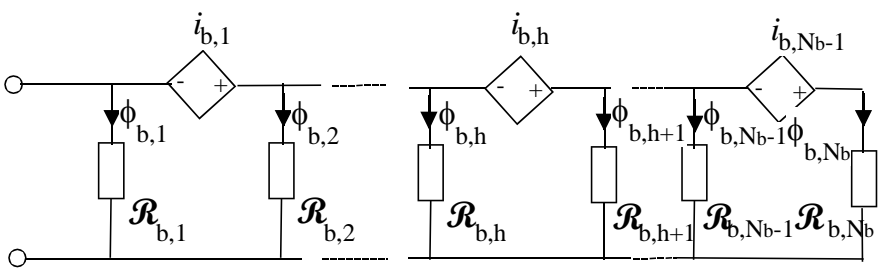

Figure 6.Reluctance model of a magnetic branch. 


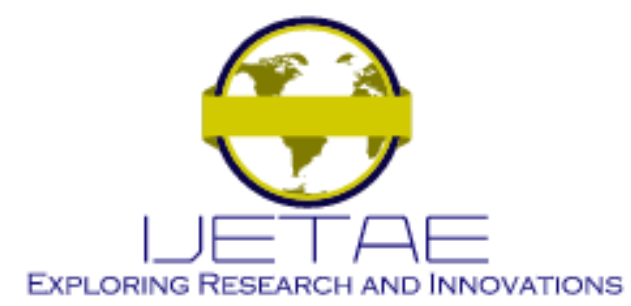

International Journal of Emerging Technology and Advanced Engineering

Website: www.ijetae.com (E-ISSN 2250-2459, Scopus Indexed, ISO 9001:2008 Certified Journal, Volume 11, Issue 09, September 2021)

The controlled sources shown in Fig. 7 represent the link between magnetic and "eddy current domain".
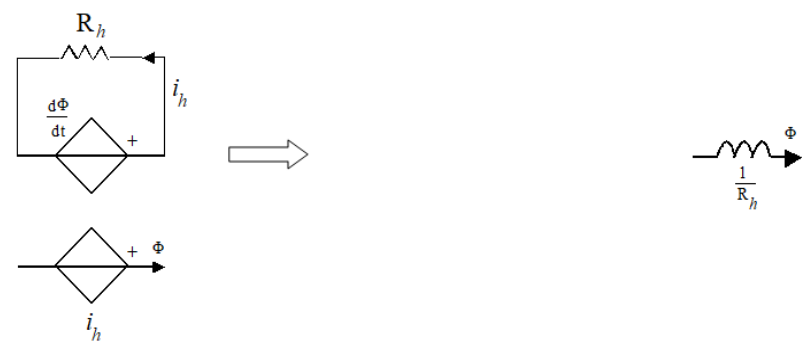

Figure 7.Coupling between magnetic and eddy current domain

The analogy with inductance, can be obtained handling the equations of the two current controlled voltage source:

$$
i_{h}=\frac{\frac{d \phi}{d t}}{R_{p}}=G_{h} \cdot \frac{d \phi}{d t}(9)
$$

A different model (Fig. 8) can be obtained using the analogy between permeance and capacitance. The gyrators employed into the model can be replaced, simply by a resistance of value $\mathrm{Gh}$.

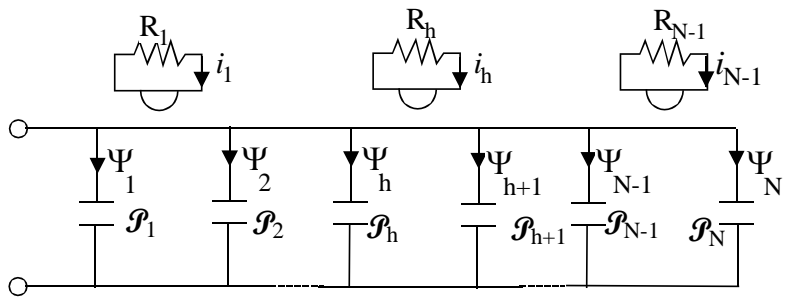

Figure 8.Gyrator-capacitor model of a magnetic branch

In the two representations, the magnetic flux and electric current distributions are the unknowns of the problems. In complex magnetic topologies, more than one magnetic branch can be needed to model the structure, in this case, a macro model is built connecting more than one block according to the structure topology. Considering an electromagnetic actuator, the magnetic model is constituted by $\mathrm{Nb}$ branches. For the generic one $\mathrm{b}$, it is possible to write a set of the equation, each of them represents the voltage Kirchhoff laws of a loop of the ladder network. Assuming the reluctance model, the equation is:

$$
\begin{aligned}
& \phi_{b, h} R_{b, h}-\frac{1}{R_{b}, h} \sum_{k=n+1}^{N} \frac{d \phi_{b, n}}{d t}- \\
& \phi_{b, h+1} R_{b, h+1}=0
\end{aligned}
$$

While assuming the gyrator-capacitor model the equation becomes:

$$
\frac{\phi_{b, h}}{P_{b, h}}-\frac{1}{R_{b, h}} \sum_{k=h+1}^{N} \Psi_{b, k}-\frac{\phi_{b, h+1}}{p_{b, h+1}}=0
$$

The solution of the entire magnetic circuit is then complete by a set of Kirchhoff laws at the terminal of each branch (represented in Fig.9 for the reluctance model and in Fig. 10 for the permeance-capacitance model):

$$
\begin{gathered}
\phi=\phi_{b}=\sum_{k=1}^{N} \phi_{b, k} \text { or } \\
\Psi=\Psi_{b}=\sum_{k=1}^{N} \Psi_{b, k}
\end{gathered}
$$

and by the voltage equation at the electric port to the external supply:

$$
\begin{aligned}
& e_{\theta x t}=R_{\theta x t} i_{\theta x t}+N_{s} \frac{d \phi}{d t} \text { or } \\
& e_{\theta x t}=R_{\theta x t} i_{\theta x t}+N_{s} \Psi(13)
\end{aligned}
$$

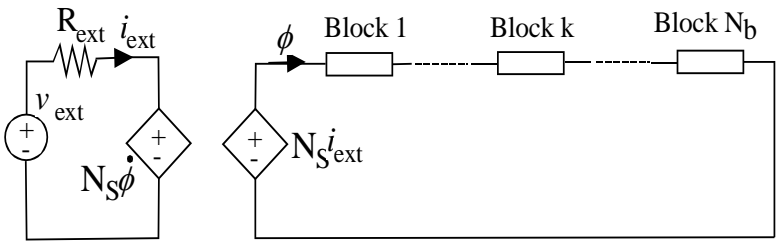

Figure 9.Reluctance macro model of magnetic structure

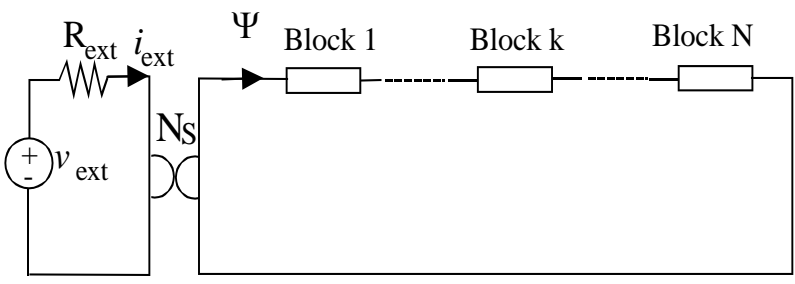

Figure 10.Gyrator macro model of magnetic structure

\section{POWER CONSIDERATIONS}

The characterization of electromagnetic devices can be done through the analysis under transient or steady-state behavior (stationary and quasi-stationary). In the second case, the interest is mainly devoted to the sinusoidal supply conditions. Any periodic waveform could be represented by a Fourier series. 


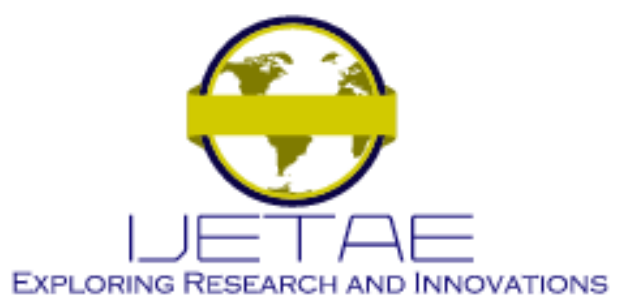

International Journal of Emerging Technology and Advanced Engineering

Website: www.ijetae.com (E-ISSN 2250-2459, Scopus Indexed, ISO 9001:2008 Certified Journal, Volume 11, Issue 09, September 2021)

Energy considerations are more significant in steadystate conditions. For this reason, it is worth it to make some deepening on the relations between magnetic and electric power for the two previous analogies.

\section{A. The reluctance-resistance analogy}

Using resistance-reluctance analogy each magnetic flux path can be described through a resistance and an inductance (complex reluctance), as shown in Fig. 11, in order to take into account eddy current. An appropriate model for eddy current will be shown in the following sections.

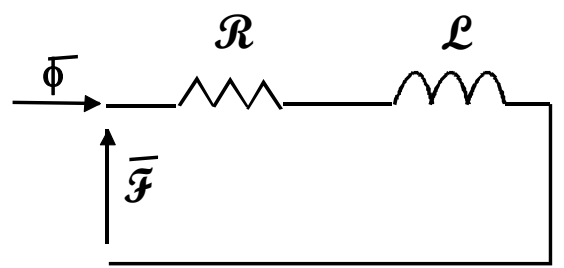

Figure 11.Complex Reluctance

Using complex reluctance $\mathrm{Z}=\mathrm{R}+\mathrm{jL}$ the relation (2) can also written as:

$$
\bar{F}=Z \cdot \bar{\phi}
$$

The complex power $\bar{A}$ in the electrical domain is defined by means of the voltage and current as:

$$
\bar{A}=\bar{V} \cdot \bar{I}^{+}=P+j Q
$$

Where $\mathrm{P}$ is the power losses due to the eddy current and $\mathrm{Q}$ is the reactive power due to the magnetic energy stored into the magnetic core. Both $\mathrm{P}$ and $\mathrm{Q}$ have the physical dimension of a power.

It is possible to define a complex "power"J also in the magnetic domain by means of flux and magneto-motive force:

$$
\bar{l}=\bar{F} \cdot \bar{\phi}^{*}=W+j E
$$

Where $\mathrm{W}$ is the stored energy into magnetic reluctance and E is the "energy" loss into the eddy current path. Both $\mathrm{W}$ and $\mathrm{E}$ have the dimension of an energy.

Substituting equations (6) and (13) into relation (16) it could be rewritten as:

$$
\bar{V} \cdot \overline{I^{*}}=j \omega \cdot Z^{*} \cdot \phi^{2}
$$

The complex electric power became:

$$
\begin{aligned}
& \bar{A}=j \omega \cdot\left(R \cdot \phi^{2}-j \omega \cdot L \cdot \phi^{2}\right)=j \omega . \\
& (W+j E)
\end{aligned}
$$

Under these considerations the resistance - reluctance analogy is not formally correct. At the same time the two ports employed to couple the electrical with magnetic domain is not "neutral" in term of energy transformation and allows to define the following identities:

$$
\left\{\begin{array}{l}
P=-\omega \cdot E \\
Q=j \omega \cdot W
\end{array}\right.
$$

\section{B. The permeance-capacitance analogy}

Considering the capacitance-permeance analogy a generic flux path can be represented as shown in Fig. 12 by means of a permeance in series with an eddy current resistance (complex permeance).

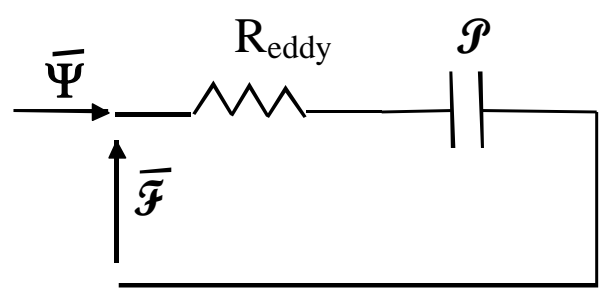

Figure 12.Complex Permeance

Defining the complex permeance $\mathrm{S}=$ Reddy $+\mathrm{jP}$ the relation (4) can be rewritten as:

$$
\bar{\Psi}=j \omega \cdot S \cdot \bar{F}(20)
$$

As done in the previous paragraph it is possible to write the complex electrical power $\bar{A}$, with the same meaning of the quantities discussed before, as:

$$
\bar{A}=\bar{V} \cdot \bar{I}^{*}=P+j Q
$$

At the same time, it is possible define a complex magnetic "power" $\overline{\mathrm{A}}$ as:

$$
\bar{A}=\bar{F} \cdot \bar{\Psi}^{*}=P_{\theta d d y}+j Q
$$

Where Peddy is the power losses due to eddy current and $\mathrm{Q}$ is the reactive power due to the magnetic energy stored into the permeance. 


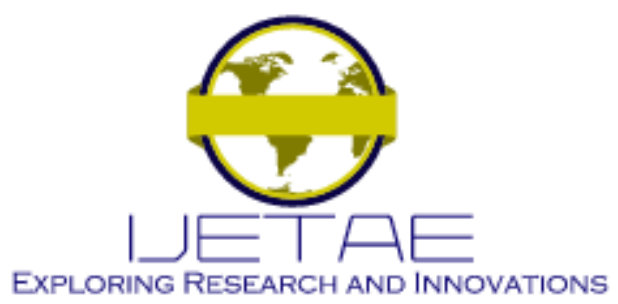

International Journal of Emerging Technology and Advanced Engineering Website: www.ijetae.com (E-ISSN 2250-2459, Scopus Indexed, ISO 9001:2008 Certified Journal, Volume 11, Issue 09, September 2021)

Substituting equations (7) and (19) into relation (20) it could be rewritten as:

$$
\bar{V} \cdot \bar{I}^{*}=\left(R_{\theta d d y} \cdot \Psi^{2}-j \frac{\Psi^{2}}{\omega P}\right)=P_{\theta d d y}-j Q
$$

\section{NON-LINEAR MODEL}

The model of magnetic nonlinearities can be faced through different techniques based on numerical algorithms (e.g. Newton-Rhapson algorithm). Each of these methods offers both advantages and drawbacks as highlighted in different work. In this work the Fixed Point technique is employed; this scheme allows linearization of the problem easily rep-resented through equivalent networks. It is based on the decomposition of the magnetic characteristic in the sum of a term that depends linearly on the magnetic flux density B and of a residual one, that it comes iteratively estimated beginning from an attempt value.

By considering the resistance-reluctance analogy the relation that alloy the magnetic induction $\mathrm{B}$ with the $\mathrm{H}$ field are expressed from the formula:

$$
H=\xi(B)
$$

In which $\xi(B)$ can be written, using a linear expression, as:

$$
\xi(B)=\frac{1}{\mu_{p f}} \cdot B+R
$$

By writing the Ampere's law for the nonlinear path it is possible to obtain the following relation:

$$
\oint H \cdot d l=\oint \frac{1}{\mu_{p f}} \cdot \frac{\phi}{s} \cdot d l+\oint R \cdot d l=F(26)
$$

In the (26) it is possible to recognize two terms: the first is the reluctance of the considered path multiplying the flux that flow in the circuit, while the second has the dimensions of a magneto motive force and it is depending from the value of the residual one.

The residual is calculated iteratively starting from a value of the $\mu_{\mathrm{pf}}$ chosen in such way that is:

$$
\mu_{p f}=\frac{\mu_{\max }+\mu_{\min }}{2}
$$

In order to assure the convergence.

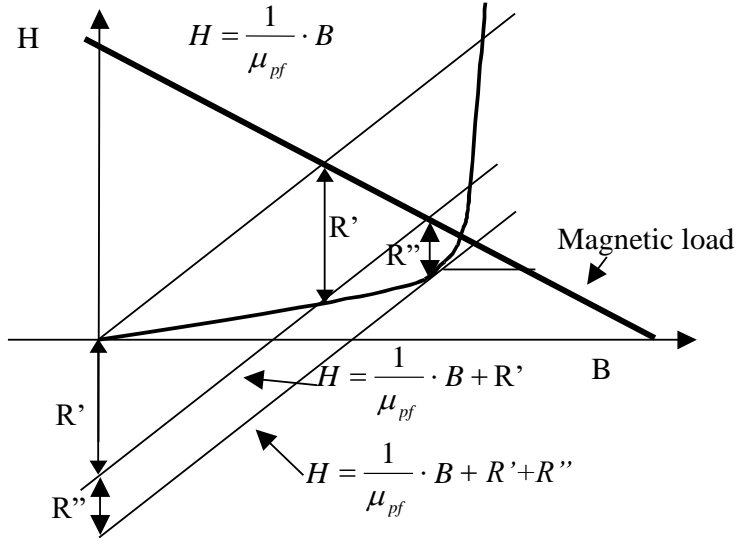

Figure 13.Fixed point interactive scheme.

By considering, now, the permeance-capacitance analogy it is possible to write the following relation:

$$
\boldsymbol{B}=\xi^{-1}(\boldsymbol{H})
$$

$\xi^{-1}(\boldsymbol{H})$ can be linearized by means of the formula:

$$
\xi^{-1}(\boldsymbol{H})=\mu_{p f} \cdot \boldsymbol{H}+W(28)
$$

Therefore, the relation that describes the flux becomes:

$$
\int \boldsymbol{B} \cdot d S=\int \mu_{p f} \cdot \boldsymbol{H} \cdot d S+\int W \cdot d S=\phi
$$

that can be also written as:

$$
\int \mu_{p f} \cdot \frac{F}{l} \cdot d S+\int W \cdot d S=\phi
$$

The magnetic flux rate, introduced in section II, becomes:

$$
\Psi=P \cdot \frac{d F}{d t}+\frac{d}{d t}(W \cdot S)(31)
$$

In the (31) it is possible to recognize two terms: the first is the permeance of the considered path multiplying the derivative of the magneto motive force; the second has the dimensions of a magnetic flux rate and it is depending from the value of the residual one.

A comparison between the two model is reported in Fig. 14. 


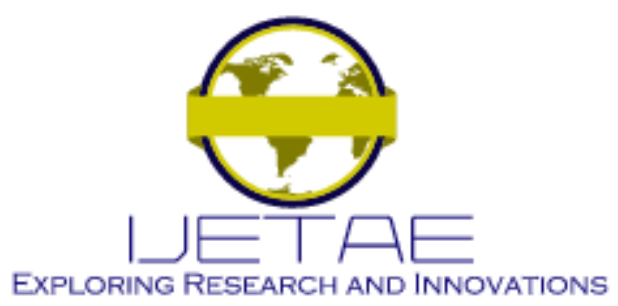

International Journal of Emerging Technology and Advanced Engineering

Website: www.ijetae.com (E-ISSN 2250-2459, Scopus Indexed, ISO 9001:2008 Certified Journal, Volume 11, Issue 09, September 2021)

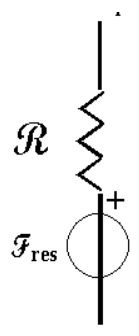

(a)

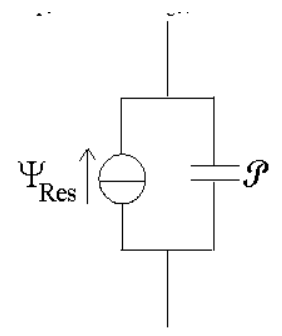

(b)

Figure 14.Model of nonlinearity into the two magnetic analogies.: (a) Reluctance Resistance (b) Permeance Capacitance

\section{Simulations Of EleCtromechanical DeVICES}

The proposed method is applied to two different cases. The first one represents an "ideal" problem that can help to study the algorithm. The second one is an axial symmetric massive magnetic core in which the eddy current phenomena are not negligible.

\section{A. Undefined length Cylinder}

To test the accuracy of the proposed method an undefined length cylinder is analyzed. The magnetic equivalent network of the core is shown in figure 15 . The structure is divided into 9 layers, each of them represents a possible path for the induced current. The results are obtained by supplying the coil with a step voltage. In figure 16 the eddy current for each layer is shown. Block 1 is the external sheet that links the major part of the flux, while block 8 represents the inner sheet. Each eddy current rises with its time constant and with a delay that is typical of diffusion into conductive media. The behaviour of the current flowing into the coil is shown in figure 16. The time constant is lower than the time constants of eddy currents. Analyzing both fig. 16 and fig. 17 is possible to see as the induced current decrease to zero (steady-state) into a time depending on the conductivity of the magnetic material.

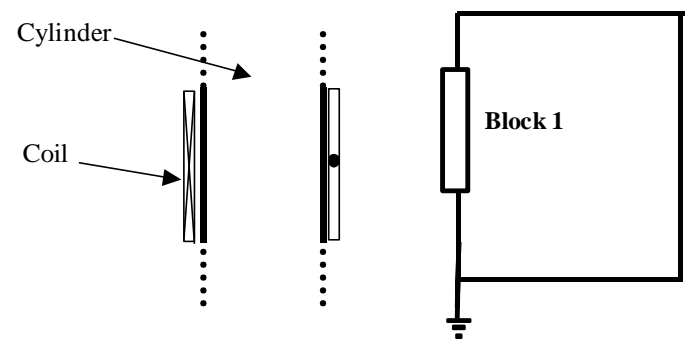

Figure 15.MEC of the cylinder

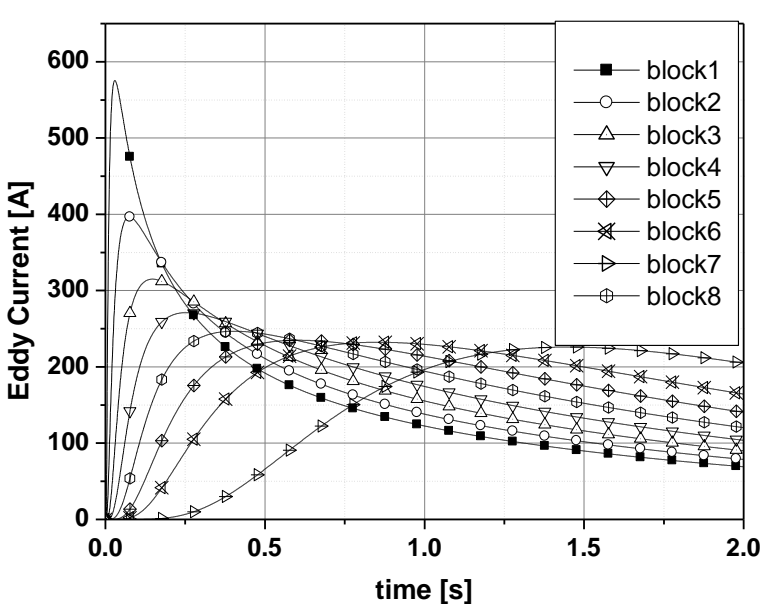

Figure 16.Eddy current inside different subdivision of the cylinder

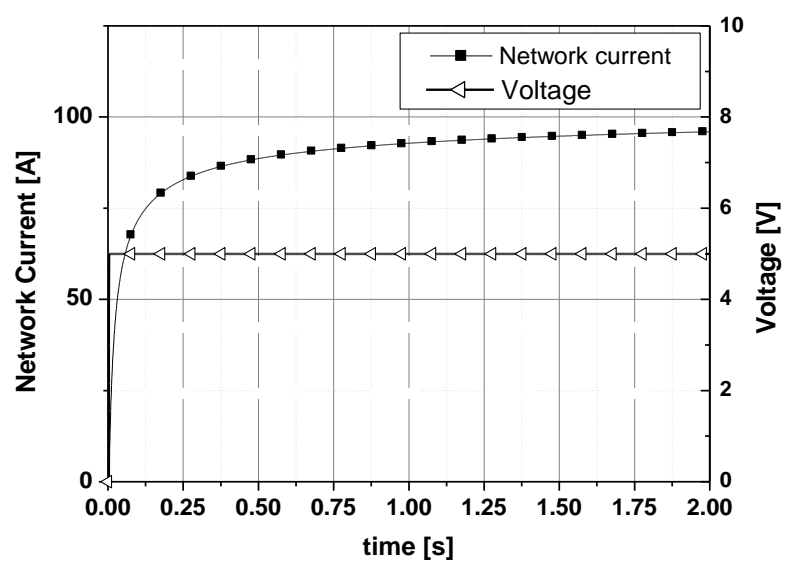

Figure 17.Network current and Supply voltage

\section{B. Axial symmetric electromagnet}

An axial symmetric electromagnet has been built to validate the simulation obtained with a set of measurements. The axial symmetric device is composed of a cylinder (internal core) surrounded by a winding, by a hollow cylinder, and by two disks representing the closures of the magnetic path. The upper disk (moving core) is supposed to remain in the closed position with a $0.45 \mathrm{~mm}$ air-gap. The prototype, shown in figure 18, is made of magnetic iron and is supplied with a 75 turns coil, and its main dimension is reported in fig. 21 together with the assumed flux tube model. 


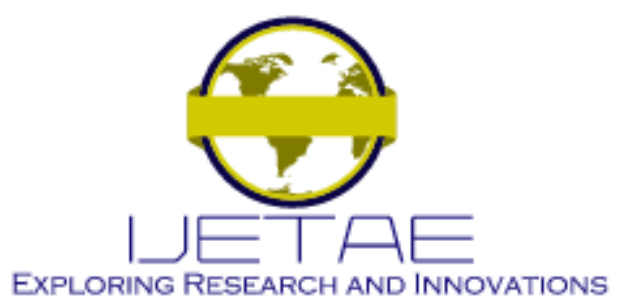

International Journal of Emerging Technology and Advanced Engineering

Website: www.ijetae.com (E-ISSN 2250-2459, Scopus Indexed, ISO 9001:2008 Certified Journal, Volume 11, Issue 09, September 2021)

Three different kinds of simulation have been carried out: transient behaviour under step voltage, transient behaviour under sinusoidal voltage, and steady-state behaviour under sinusoidal voltage supply conditions.

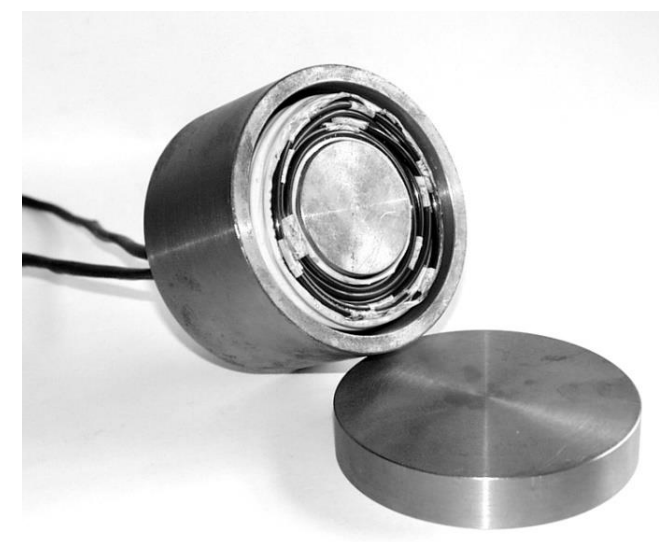

Figure 18.Axial-symmetric Electromagnet

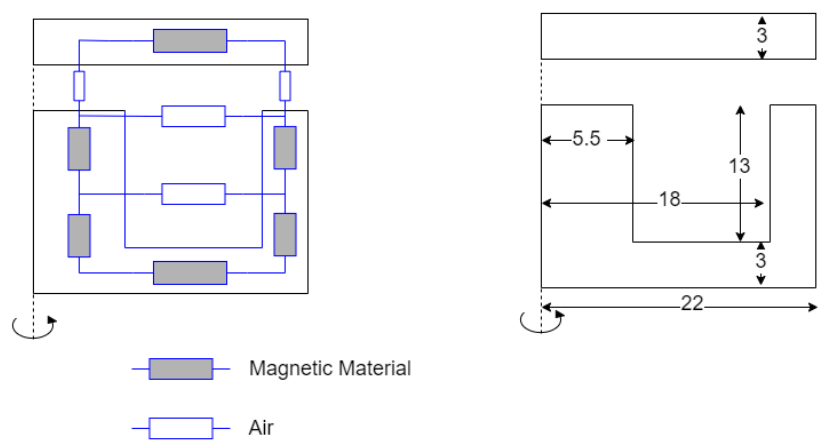

Figure 19.MEC Model of electromagnet

\section{Transient behaviour under step voltage supply conditions}

Different supply voltage values have been considered. The magnetic branches of the circuit have been divided into ten layers and the MEC model is composed of twelve blocks. In figure 20 the simulated and measured current of the coil under a step voltage test is re-ported. As can be seen, the agreement between the curves is more than satisfactory.

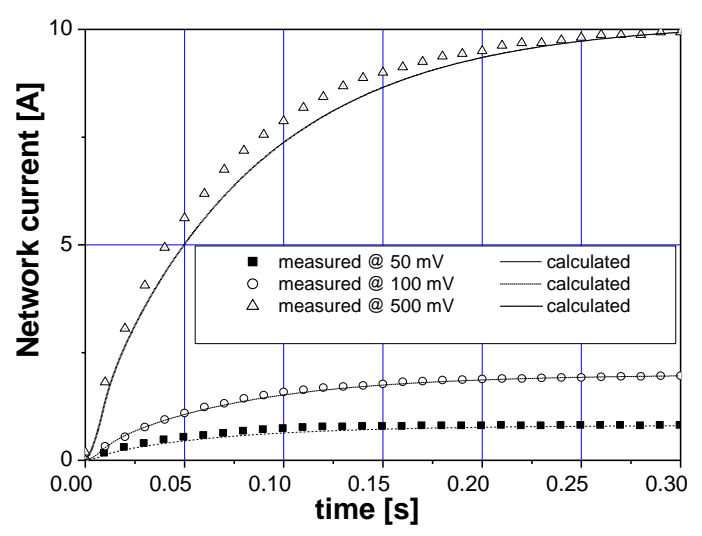

Figure 20.Comparison between simulated and calculated network current

\section{Transient behaviour sinusoidal voltage supply conditions}

Some simulations have been performed under sinusoidal supply with a frequency of $10 \mathrm{~Hz}$. Figure 21 reports the eddy current computed inside the central core. Layers are numbered starting from the more external one (ten layers have been considered). In fig. 22 the time variation of magnetic flux density is reported. As it can be seen the flux distribution is limited to the five more external layers due to the eddy currents shielding effects. Moreover, the nonlinear behaviour of the core introduces a significant distortion in the waveform. In figure 23 the transient behaviour of the absorbed network current is reported. A final consideration regards the significant difference, in terms of the time constant, among the electrical and magnetic quantities due to the presence in the MEC model of several poles.

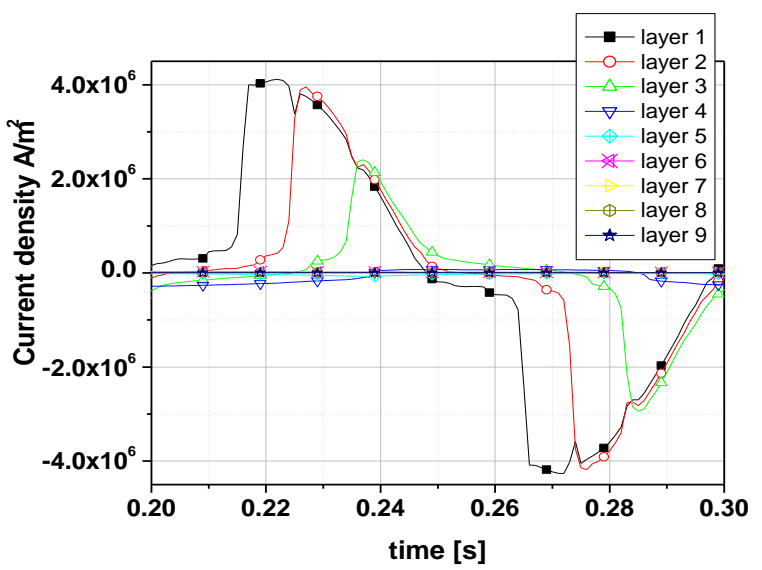

Figure 21.Eddy current density for each layer into a period (frequency $=10 \mathrm{~Hz}$ ) 


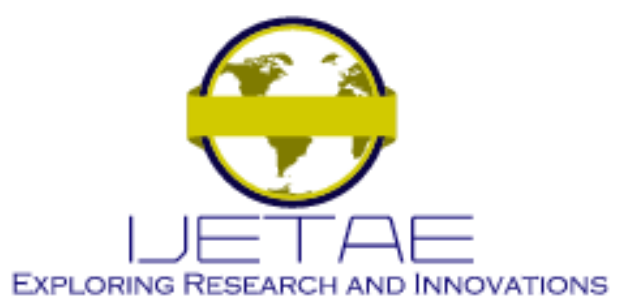

International Journal of Emerging Technology and Advanced Engineering

Website: www.ijetae.com (E-ISSN 2250-2459, Scopus Indexed, ISO 9001:2008 Certified Journal, Volume 11, Issue 09, September 2021)
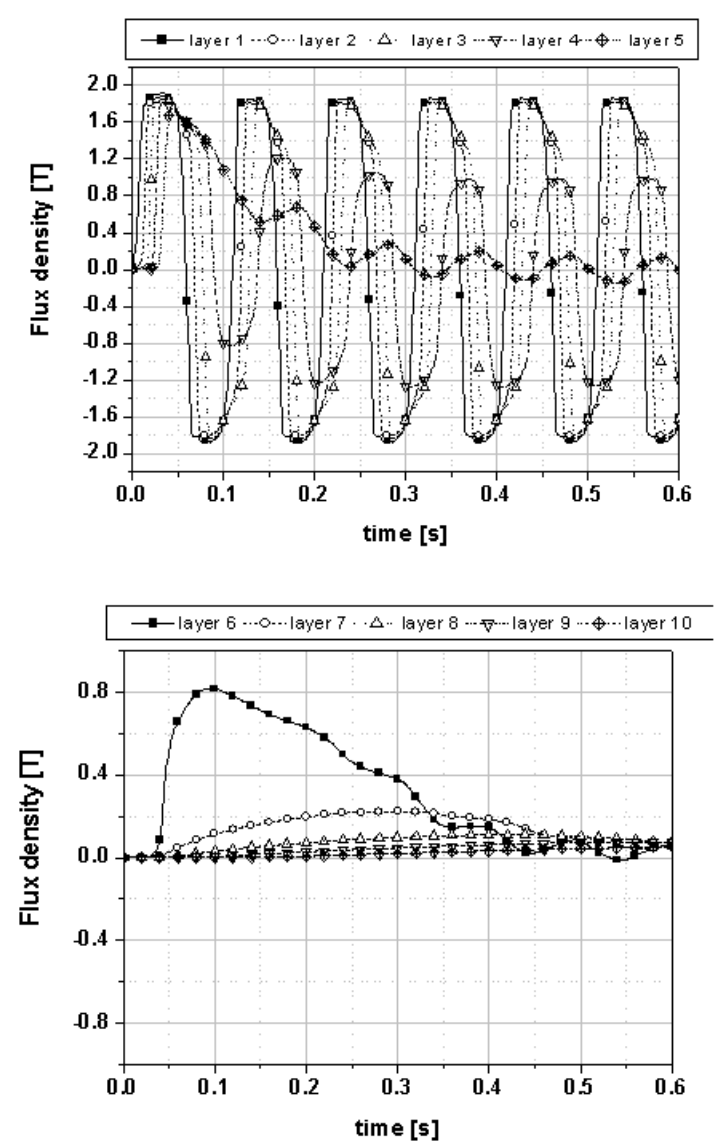

Figure 22.Flux density into layers 1-5 and into layers 6-10

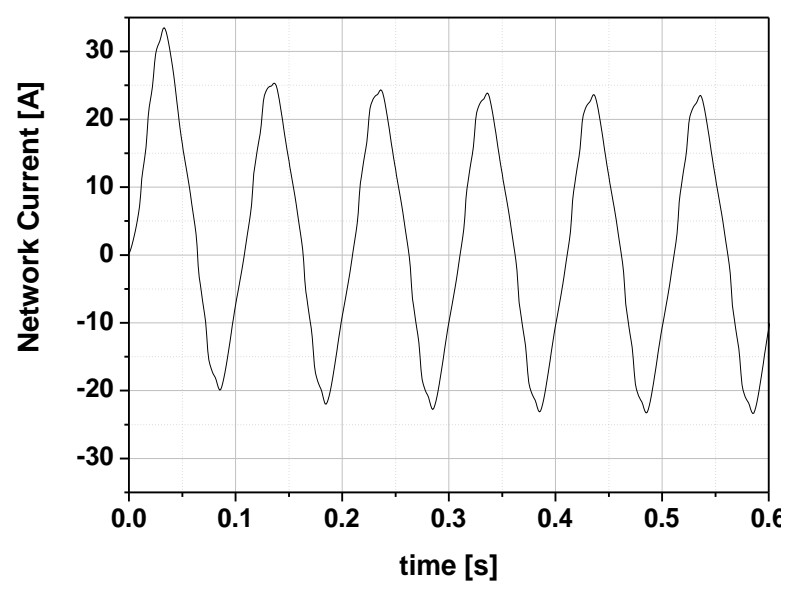

Figure 23.Network current absorbed by the device
E. Steady state behaviour under sinusoidal voltage supply conditions

In Fig. 24 the comparison of the MEC approach with experimental data are reported under sinusoidal steadystate supply conditions. MEC approach uses, as in the previous simulations, twelve blocks to model the magnetic circuit taking into account also leakage flux. Eddy current blocks are subdivided into 6 flux tubes. As it can be seen the agreement be-tween supply currents is more than satisfactory.

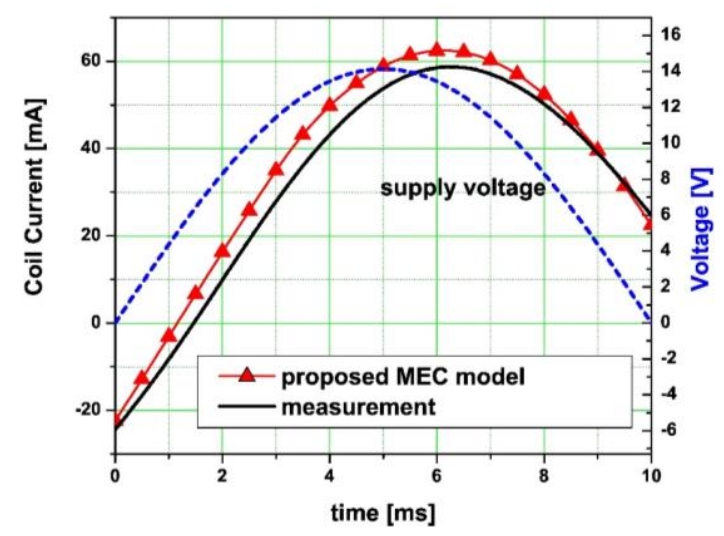

Figure 24.Computed and experimental supply current under sinusoidal supply

\section{CONCLUSIONS}

In this paper, we presented a method to model electromechanical systems based on an analogy with electrical circuits. The method has been applied to the study of a real problem and is validated through experimental measurements. It is shown how an accurate model taking into account nonlinear magnetic phenomena and eddy current, can fix perfectly with measurements and be a valid analysis tool.

\section{REFERENCES}

[1] E.R.Laithwaite "Magnetic equivalent circuits for electrical machines", PROC. IEE, vol 115, №11, pp. 1805-1809, November 1967

[2] Johnson et al.: "Parametrized linear MEC for analysis and design of radial flux magnetic gears-part I:Implementation", IEEE Trans. on energy conversion, vol. 33, no. 2, june 2018

[3] Sudhoff et al.: "Magnetic equivalent circuit based scaling laws for low frequency magnetic devices", IEEE Trans. on energy conversion, vol. 28, no. 3, september 2013

[4] Cale et al.: "Accurately modeling EI core inductors using a high fidelity magnetic equivalent circuit approach", IEEE Trans. Mag. , vol. 42, no. 1, january 2006 


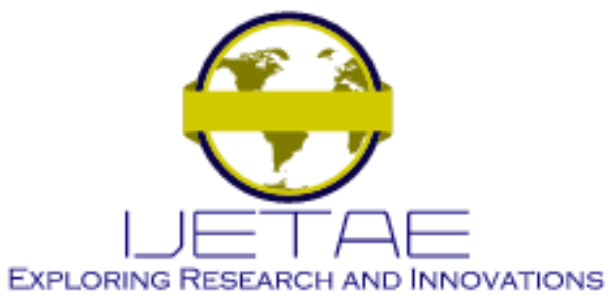

International Journal of Emerging Technology and Advanced Engineering

Website: www.ijetae.com (E-ISSN 2250-2459, Scopus Indexed, ISO 9001:2008 Certified Journal, Volume 11, Issue 09, September 2021)

[5] B. N. Cassimere et al.: "Evolutionary design of electromagnetic and electromechanical devices", 1-4244-0947-0/07 - 2007 IEEE.

[6] C.J. Carpenter "Magnetic equivalent circuits", PROC. IEE, vol 115, $\mathrm{N}^{\circ} 10$, pp. 1503-1511, October 1968

[7] R.W. Buntenbach, "Analogous between magnetic and electrical circuits", Electronic Products, pp 108-113, October 1969

[8] R.W. Buntenbach, "A comprehensive circuit model for the electromechanical/acoustic transducer", IEEE Trans. on Audio and Elec-troacoustics, vol. AU-19, pp 249-252, September 1971

[9] C.J. Carpenter "A network approach to the numerical solution of eddy-current problems”, IEEE Trans. Mag., Vol. Mag-11, Sept. 1975 , pp $1517-1522$

[10] P.G. Blanken, J.J.L.M. Van Verklen, "Modeling of electromagnetic systems“, IEEE Trans. Mag., Vol. 27, Nov. 1991, pp 4509-4515

[11] D.C. Hamill, "Lumped equivalent circuits of magnetic components: the gyrator-capacitor approach", IEEE Transactions Power Electronics, vol. 8, April 1993, pp 97-103,

[12] Benmessaoud et al.: "Combining the magnetic equivalent circuit and Maxwell-Fourier method for Eddy-Current loss calculation", Math. $\begin{array}{llll}\text { Comput. } & \text { Appl. } & 2019, & \text { 24(2), }\end{array}$ https://doi.org/10.3390/mca24020060

[13] Sixdenier et al.:'Dynamical models for Eddy Current in ferromagnetic cores introduced in an FE-tuned magnetic equivalent circuit of an electromagnetic relay", IEEE Trans.Mag., vol. 44, no. 6, june 2008

[14] M. Yilmaz and P. T. Krein, "Capabilities of finite element analysis and magnetic equivalent circuits for electrical machine analysis and design," 2008 IEEE Power Electronics Specialists Conference, Rhodes, 2008, pp. 4027-4033, doi: 10.1109/PESC.2008.4592584.

[15] Benmessaoud, Y.; Dubas, F.; Hilairet, M. "Combining the Magnetic Equivalent Circuit and Maxwell-Fourier Method for Ed-dy-Current Loss Calculation”. Math. Comput. Appl. 2019, 24, 60

[16] J. Wang and J. Zhu, "A Simple Method for Performance Prediction of Permanent Magnet Eddy Current Couplings Using a New Magnetic Equivalent Circuit Model," in IEEE Transactions on Industrial Electronics, vol. 65, no. 3, pp. 2487-2495, March 2018, doi: 10.1109/TIE.2017.2739704.
[17] S. Saeed, J. García and R. Georgious, "Modeling of variable magnetic elements including hysteresis and Eddy current loss-es," 2018 IEEE Applied Power Electronics Conference and Exposition (APEC), San Antonio, TX, USA, 2018, pp. 1750-1755, doi: 10.1109/APEC.2018.8341254

[18] M. Chiampi, D. Chiarabaglio, M. Repetto, "An accurate investigation on numerical methods for nonlinear magnetic field problems" Journal of Magnetism and Magnetic Materials, Vol. 133, pp. 591-595, 1994.

[19] A.D. Brown, J.N. Ross; K.G. Nichols,"Time-domain simulation of mixed nonlinear magnetic and electronic systems", IEEE Trans. Mag., Vol. 37, 2001, pp 522 -53

[20] O.H. Zinke, W.F. Schmidt, "Linear AC magnetic circuit Theory", IEEE Trans. Mag., Vol. 29, Sept. 1993, pp 2307 - 2212

[21] D.C. Hamill, "Gyrator-capacitor modeling: a better way of understanding magnetic components", APEC '94. Conference Proceed-ings, Feb 1994,pp 326-332

[22] M.Eaton,"Modeling magnetic devices using the gyrator re-cap core model "Northcon/94 Conference Record pp 60-66

[23] D. Shmilovitz, I. Yaron, S. Singer, "Transmission-line-based gyrator" IEEE Trans. Circuits and Systems I, Vol. 45, Apr. 1998,pp 428-433

[24] M. Piron,P. Sangha, G. Reid,T.J.E. Miller,D.M. Ionel,’Rapid computer-aided design method for fast-acting solenoid actuators", IEEE trans. on Ind. App., Vol 35, N 5,pp. 991-999,Sept.-Oct.1999

[25] Grandi, G.; Massarini, A.; Reggiani, U.; Sancineto, G, "Laminated iron-core inductor model for time-domain analysis" Pow-er Electronics and Drive Systems 2001. Proceedings. 4th IEEE International Conference on , Volume: 2 , 2001 pp: 680 -686

[26] Saeed, S.; Georgious, R.; Garcia, J. Modeling of Magnetic Elements Including Losses-Application to Variable Induc-tor. Energies 2020 , 13, 1865. https://doi.org/10.3390/en13081865

[27] D. Ceylan, L. A. J. Friedrich, K. O. Boynov and E. A. Lomonova, "Convergence Analysis of the Fixed-Point Method With the Hybrid Analytical Modeling for 2-D Nonlinear Magnetostatic Problems," in IEEE Transactions on Magnetics, vol. 57, no. 2, pp. 1-5, Feb. 2021 